\title{
Artículos
}

\section{Metaespacio: la cáscara cosmopolita de un entorno inventado. Representaciones sobre el Barrio Italia, Santiago de Chile}

\section{Metaspace: The cosmopolitan skin of an invented environment. Representations about Barrio Italia, Santiago de Chile}

\author{
Rodrigo Hidalgo ${ }^{\mathrm{a}}$ \\ Voltaire Alvarado ${ }^{b}$ \\ Daniel Santana ${ }^{c}$ \\ Alex Paulsen $^{\mathrm{d}}$
}

\section{Resumen}

El fetiche gentrificador ha devenido en paradigma dentro de las ciencias sociales, además de su validación tanto en lo público como en lo privado. Por ello, este trabajo levanta al metaespacio como dispositivo descriptivo sobre tramas ontológicas y epistemológicas visualizadas en zonas centrales.

Con una metodología adaptada del ritmanálisis de Henri Lefebvre, se trabajan elementos materiales y subjetivos de producción metaespacial sobre el Barrio Italia de Santiago de Chile, localizado en la comuna de Providencia. Apreciada por dis-

a Profesor de la Pontificia Universidad Católica de Chile, Instituto de Geografía, Doctorado en Geografía. Dirección postal: Av. Vicuña Mackenna 4860, Macul, Santiago de Chile. Correo electrónico: rhidalgd@uc.cl

${ }^{\mathrm{b}}$ Candidato a doctor en Geografía, en la Pontificia Universidad Católica de Chile, Instituto de Geografía. Dirección postal: Av. Vicuña Mackenna 4860, Macul, Santiago de Chile. Correo electrónico: vcalvarado@uc.cl

' Candidato a doctor en Geografía, en la Pontificia Universidad Católica de Chile, Instituto de Geografía. Dirección postal: Av. Vicuña Mackenna 4860, Macul, Santiago de Chile. Correo electrónico: 1dsantana@uc.cl

${ }^{\text {d }}$ Estudiante del doctorado en Geografía, Pontificia Universidad Católica de Chile, Instituto de Geografía. Dirección postal: Av. Vicuña Mackenna 4860, Macul, Santiago de Chile. Correo electrónico: aapaulse@uc.cl

Nota de los autores: Este trabajo se adscribe al Fondecyt regular núm. 1095222, "La transformación de las áreas centrales: reestructuración comercial y elitización (gentrificación) residencial. El caso de Santiago, Valparaíso y Viña del Mar". 
tintos actores, la zona representa una interesante faceta neoliberal que, desarrollada desde una posición de activismo académico, puede arrojar luces sobre el desenvolvimiento espacial neoliberal.

Palabras clave: metaespacio; activismo académico; ritmanálisis; espacio geográfico.

\begin{abstract}
The gentrification fetish has become a paradigm within the Social Sciences, in addition to his validation in the public as in the private. Therefore, this work raises the meta-space as a descriptive device on ontological and epistemological plots visualized in central zones.

With a methodology adapted from the rhythmic analysis of Henri Lefebvre, material and subjective elements of meta-spatial production are worked on the Barrio Italia in Santiago de Chile, located in the commune of Providencia. Appreciated by different actors, the area represents an interesting neoliberal facet that, developed from a position of academic activism, can shed light on neoliberal spatial development.
\end{abstract}

Keywords: metaspace; academic activism; rhythmanalysis; geographical space.

¿Es la libertad, también, un producto?

HENRI LEFEBVRE

La teoría crítica en geografía, definida como aquella que asume una posición de cuestionamiento tanto a paradigmas tradicionales como al statu quo de las relaciones sociales dominantes -incluyendo no sólo a las corrientes marxistas, sino también a las postestructuralistas-, se debate entre dos dimensiones antagónicas entre sí: un ontologismo, que busca teorizar las propiedades sociales del espacio geográfico; y un epistemismo, basado en aproximaciones heurísticas que buscan comprender la espacialización de la vida social, en el marco estructural del capitalismo. Por la primera senda se llega a decir que el espacio se construye, y por la segunda, que es un producto.

Los ontologistas reflexionan sobre ciertas cualidades sociales del espacio geográfico, destacando su capacidad de agencia social (Lussault, 2015); las dimensiones reales, imaginarias y de alteridad del espacio -los tres espacios- (Soja, 1996); sus propiedades de interacción, multiplicidad y diferencia (Massey, 2012); e incluso sobre las instancias inmateriales del lugar (Lindón, 2011). Por otro lado, los epistemistas -sobre todo anglosajonesabordan esta categoría esencial desde las leyes espaciales del capitalismo 
(Harvey, 2006), las escalas geográficas producidas por el capital (Smith, 2012), y la producción capitalista de la naturaleza (Peet et al., 2011; Castree, 2013). De forma coincidente, todo lo anterior se discute en el marco de la descripción y denuncia de las transformaciones que el capital desarrolla en el espacio geográfico.

Aunque algunos de esos autores transitan entre esas dos categorías - quizás Doreen Massey, David Harvey y Edward Soja-, la primera tiende a producir geografías particularistas que exaltan la diferencia, mientras que la segunda construye, o se vale, de geografías metonímicas ${ }^{1}$ que universalizan ciertos procesos socioespaciales, propios de un determinado contexto.

Dentro de la segunda corriente emerge la categoría de gentrificación, erigiéndose con el transcurso del tiempo en un fetiche epistemológico ${ }^{2}$ capaz de explicar y analizar las transformaciones en determinadas áreas espaciales, teniendo a la población como unidad mínima descriptiva y a la localización como un elemento topológico básico e inmóvil. ${ }^{3}$

Este término, acuñado por la socióloga marxista Ruth Glass durante la década de 1960, se articula como manifestación socioespacial de los cambios en la renta del suelo urbano, concentrando los casos de estudio en ciudades anglosajonas, caracterizadas a partir del desplazamiento y sustitución de un grupo social por otro de mayores ingresos, precisamente en áreas centrales (Glass, 1989). Esto se ha ampliado en los estudios para zonas turísticas, áreas de protección silvestre, franjas periurbanas o incluso para la transformación urbana de predios agrícolas (Bridge, 1995; Wacquant, 2008; Smith, 2012; Wyly, 2015).

A partir del uso de esta categoría, subyacen tres circunstancias metonímicas usuales en las que concurren tanto la teoría social como la geografía humana crítica anglosajona:

1) Un proceso socioespacial particular de un contexto de capitalismo avanzado, tal como lo es la reinversión de capital en las áreas centrales por parte de agentes financieros e inmobiliarios transnaciona-

${ }^{1}$ Esta idea de metonimia busca ilustrar la captura de las propiedades del espacio geográfico por conceptos y categorías que, como se verá más adelante, reducen los principios de escala, movilidad y agencia que la geografía ha establecido como principios básicos en su objeto de estudio: el espacio geográfico.

${ }^{2}$ El fetiche como concepto tiende a ser mancillado en sus propósitos. Sin embargo, la Real Academia de la Lengua Española lo define, en parte, como "objeto de culto al que se atribuyen poderes sobrenaturales". Fuente: http://dle.rae.es/?id=HpHhvVa (6 de enero de 2017).

3 En geografía y teoría urbana hay numerosos ejemplos de esas metonimias: la modernidad urbana y el desarrollo definidos en función del contexto geohistórico noroccidental -que han sido objeto de la crítica postcolonial (Robinson, 2006), y en la que incurren también estos autores-o las ciudades globales. 
les, implica la sustitución de clases trabajadoras originarias por yuppies o bobos -del inglés burgueses y bohemios-, extendiéndose como medio de interpretación a otros contextos periféricos de las metrópolis del Norte y Sur Global (Lees et al., 2016), en los cuales no necesariamente operan ni los mismos agentes, ni las mismas operaciones de captación de rentas, ni tampoco las mismas dinámicas de desvalorización.

2) Este término y los procesos que describe tienden a masificarse en medios de comunicación y grupos sociales, convirtiendo a la contestación social y sus demandas en cuerpos adyacentes a la gentrificación como código explicativo del capital como agente y del Estado como estructura. Estas prácticas hegemónicas se ejemplifican en la planificación urbana neoliberal para el caso chileno, donde la gentrificación se asume como una oportunidad para propiciar la integración social en las ciudades a través de la proximidad espacial (Sabatini y Brain, 2008).

3) Finalmente, en el campo de la producción científica acontece, como bien lo señala Pereira, un proceso de vaciamiento sobre la gentrificación, al ampliarse su campo de acción para explicar múltiples procesos y ninguno al mismo tiempo, con la consecuencia de una manipulación ideológica al servicio de lo ya comentado (Pereira, 2016a; 2016b).

En consecuencia, este trabajo propone una crítica necesaria a la gentrificación como fetiche epistemológico e instrumento ideológico que, sustentado en lo anterior, busca generar una discusión sobre el enfoque teórico y metodológico que va más allá de la crítica por la crítica. En ello se presenta al metaespacio como categoría de enlace entre lo producido y construido, retomando el carácter riguroso y deliberante propio de la descripción geográfica, sin pretender instalar una hegemonía, sino discutir con aquellas categorías que han sido consolidadas como tales. Ciertamente, espera también ser una herramienta que aporte al activismo académico, ${ }^{4}$ en la

${ }^{4}$ El activismo alude al compromiso ideológico y doctrinario de las personas que forman parte de algún movimiento social o político. Es un compromiso constante por determinadas convicciones que asumen como verdades insoslayables. Por eso se alude también a la militancia como una forma de vida, donde la dedicación a transmitir esas ideas es de máximo compromiso. El activismo académico, por su parte, implica tomar partido de las construcciones teóricas propias, la elaboración de conceptos y otras acciones derivadas del cotidiano, como una forma de manifestar la constante producción y reproducción de las formas de explotación y expolio a las que se someten los académicos de un grupo determinado. Puede ejecutarse tanto en la comunicación escrita de los trabajos, como también en la exposición de ellos a distintos 
medida que el metaespacio provea de formas alternativas de producir y leer el espacio urbano.

A partir del muy sonado y publicitado caso de supuesta "gentrificación" sobre el Barrio Italia en la ciudad de Santiago de Chile, se ha buscado caracterizar distintos ritmos y ciclos de producción material y subjetiva del espacio, a partir de algunas de las categorías descritas por Henri Lefebvre en su obra Ritmanálisis (2007), donde se abordan prácticas de la vida cotidiana que construyen y producen espacio, entregando un campo objetual robusto al desarrollo del metaespacio.

Finalmente, se recogen los insumos descritos para retornar a la observación de la gentrificación que, entre otros aspectos, implicaría un reduccionismo mayúsculo en la descripción de lo acontecido en la zona de estudio. Esto desvirtúa y silencia las relaciones espaciales, emergiendo expresiones políticas e instrumentales como decir, ¡miren allí, ese barrio se gentrificó!

\section{El metaespacio: de noción a categoría crítica}

\section{Un breve estado del arte: la polisemia del metaespacio}

El metaespacio ha sido utilizado en la literatura anglosajona bajo múltiples acepciones y roles. Primero, como una adjetivación sobre la cognición espacial, y luego, como concepto revelador de aquellas espacialidades subjetivas localizadas en planos no materiales. Comprende un gran número de esferas, incorporando lo político, lo ideológico, la literatura, los mundos imaginarios, el poder, el capital, la reterritorialización, las ciudades, la ciberciudad, las líneas múltiples de flujos, las dicotomías entre los espacios públicos y privados, los espacios de experiencias en lugares prístinos, el turismo, los metamundos, las metacomunidades, los metalugares, la cartografía y el arte, así como el protolenguaje, los comportamientos, los hiperespacios y las geografías de la ficción. Su presencia es, sin duda, amplia y diversa en el ámbito de las ciencias geográficas.

Dentro de los casos mencionados, el metaespacio se configura como adjetivación de fenómenos espaciales materiales, mientras que en otros campos de la geografía se aplica como herramienta en la participación del diseño de espacios públicos, o como puente en asociación a una metarrealidad entre lo material e inmaterial en la ciudad, sobre todo a partir de las redes de infor-

públicos, tanto universitarios como sociales. Por tal motivo es una forma de pensamiento libre, ajeno a la coerción política o la coaptación de grupos económicos o de movimientos sociales predeterminados. 
mación y su infraestructura (Boyer, 1992). El metaespacio aparece, entonces, como categoría verificadora de las relaciones espaciales ocultas, tanto a nivel construido como de experiencias. Raoul Bunschoten, por ejemplo, ha denominado a esta categoría como una segunda piel de la tierra (2003).

Posicionado desde la arquitectura posmoderna, este último autor utiliza la adjetivación mencionada como segmentos de una segunda piel espacial, retratando sus tramas temporales. Así, señala que los “espacios en que podemos ver temporalidades son metaespacios", destacando que la ontología metaespacial posee un "innato carácter efímero. Éste es el sitio de la búsqueda del conocimiento; éste es el contenedor del manejo de los procesos de conocimiento, pero también es un vehículo para la búsqueda del significado del caos dinámico en el que vivimos" (Bunschoten, 2003: 59).

El trabajo de Bunschoten es clave para la presente propuesta teórica y descriptiva, pues abre una puerta a las definiciones aquí elaboradas, abordando aquello que denomina como caos dinámico. Esto, porque devela producciones concretas de espacio fijas y móviles, las que se suceden con diferentes intensidades y velocidades, acusando ciclos de inversión de capital fijo, en lo material; y producción de relaciones dinámicas en la vida cotidiana de las personas, en lo subjetivo. La llamada segunda piel se convierte, entonces, en una subjetividad permeable a ser transformada desde el sujeto (Bunschoten et al., 2001).

\section{El metaespacio como una categoría de teoría espacial crítica}

Zanjar las diferencias entre geografías ontologistas y geografías epistemistas implica recurrir a una lógica dialéctica que disuelve las tensiones entre pares conceptuales - del tipo particular/universal, visible/no visible, real/imaginario, sujeto/estructura- mediante categorías mediadoras (Lefebvre, 1970). El metaespacio propuesto aquí sería una categoría capaz de superar la tensión entre lo particular que abordan los ontologistas, y lo universal conceptualizado por epistemistas. Por lo tanto, la acepción de metaespacio desarrollada en este trabajo se inscribe como una crítica a la gentrificación, revisando el caso de Barrio Italia, al mismo tiempo que pretende una propia definición ante la polisemia presentada en lo anterior.

Ella propone adaptar un término propio de la lingüística a la geografía humana, el metalenguaje, definido como un lenguaje utilizado para hablar de otro lenguaje. ${ }^{5}$ Esto implica señalar que es posible construir un metalenguaje

${ }^{5}$ RAE: http://dle.rae.es/?id=P5BE9Pe (27 de enero de 2017). 
geográfico o lenguaje espacial -ontología no del espacio como objeto, sino de su producción- útil para descifrar diferentes espacios que guardan similitudes y diferencias, aboliendo así el sesgo entre particularidad y universalidad que aqueja al conjunto de determinadas teorías geográficas y urbanas.

Desde este punto de vista, el metaespacio puede ser definido como una trama que superpone distintos ciclos y ritmos de producción material y reproducción simbólica del espacio, así como de alienación socioespacial. Codificar esa trama requiere recomponer la yuxtaposición de ciclos y ritmos de esos tres tipos de producción del espacio: producción material, reproducción simbólica y alienación socioespacial; algo que facilita identificar la construcción de singularidades y generalidades geográficas, apoyándose directamente en la metodología del ritmanálisis propuesta por Lefebvre (2007), como será discutido en el próximo apartado. Por el momento resulta necesario ejemplificar en qué consiste esa ontología de procesos productores de espacio.

\section{La triada del metaespacio}

Un breve ejemplo geohistórico ilustra este tipo de procesos metaespaciales: la revolución capitalista ocurrida en Chile desde 1973 (Gárate, 2012). Antes de esa fecha, la forma predominante de producción del espacio se sostuvo en la tendencia a socializar los excedentes producidos no sólo de la actividad extractiva de materias primas, sino también los de la industria privada, gestándose una urbanización acelerada, focalizada en los puntos de gestión de rentas, como el caso de la minería del cobre, principalmente en Santiago de Chile y las ciudades más dinámicas que actuaban como polos industriales. A la capital chilena se le sumaban Valparaíso, Concepción y Antofagasta, entre las más significativas en el marco del proyecto socialista que, entre 1970 y 1973, materializó la utopía de un gobierno popular (Valdivia et al., 2006).

Las elites chilenas, que en ese entonces ya mostraban cierto patrón de diversificación económica en áreas estratégicas como la industria, las finanzas y los servicios, construyeron una contra-utopía: imaginaban un espacio nacional prístino de experimentos socialistas, organizado desde la uniformidad de ventajas comparativas regionales, con el fin de explotar aquellas materias primas de mayor impacto; y que, finalmente, actuaran sólo bajo un sólido criterio de descentralización estatal, augurando revertir las tendencias a la socialización y redistribución de excedentes.

El relato anterior apunta a sentar las bases de la tradición rentista de la sociedad chilena -especialmente en la elite-, que con el neoliberalismo se 
hace transversal a casi todas las clases sociales. Desde aquí pueden advertirse, en la producción del metaespacio, al menos tres dimensiones: primero, las formas de alienación socioespacial, que abarcan las dinámicas percibidas, concebidas y vividas como disociación de determinadas facciones y clases sociales en sus espacios producidos; en segundo término, las formas de producción material del espacio, que incluyen las relaciones socioespaciales de subsistencia; y, finalmente, las formas de reproducción simbólica del espacio, que garantizan cierta estabilidad de esas relaciones -mitos e imaginarios, ideologías y utopías-. Estos procesos se desarrollan a continuación, acompañándose de algunos elementos empíricos.

Formas de alienación socioespacial. Son el conjunto de prácticas que disocian en lo percibido, concebido y vivido a sujetos y grupos sociales de sus capacidades para producir y reproducirse en sus espacios. Con las transformaciones neoliberales en Chile, se produjo una formalización distópica de estas representaciones a partir de una serie de procesos de alienación socioespacial: se expulsaron habitantes de poblaciones construidas en localizaciones centrales a las periferias -expolio urbano-; se produjo una contrarreforma agraria que convirtió a campesinos en asalariados de la agroindustria de exportación -expolio rural-; y se incrementó la explotación del trabajo mediante la reducción sistemática de salarios y la ilegalización de sindicatos (Hojman, 1974). Con matices, y validando la condición excepcional de sitio en el sentido geográfico, la realidad territorial del Chile contemporáneo bien puede resumirse en estas tres afirmaciones.

Formas de producción material del espacio. Esta segunda agrupación incluye la espacialización de las relaciones sociales de producción, ya sea de nivel macrosocial o microsocial en la escala de lo cotidiano. Las formas de producción del espacio urbano comenzaron a develar el creciente poder de los bloques de poder financiero-inmobiliarios recién constituidos a finales de la década de 1990 en ciudades centrales como Santiago de Chile, la que dejó su posición metropolitana para convertirse en una macrozona urbana combinada sobre una totalidad contradictoria, junto a otras urbes aproximadas por la materialización del capital en el espacio, como es el caso de la conurbación litoral Valparaíso-Viña del Mar y Rancagua hacia el sur (Arenas et $a l ., 2003$ ). La trama espacial chilena se convirtió en un conjunto de corredores, areolas y archipiélagos urbanizados, facilitadores en la extracción de recursos naturales y, también, en la extracción de rentas del suelo urbano, vinculadas a actividades habitacionales, comerciales o turísticas.

Formas de reproducción simbólica del espacio. El último conjunto abarca a la agrupación de representaciones sociales de los espacios -imaginarios, ideologías y utopías- que contribuyen a perpetuar, ajustar o transfor- 
mar creativamente las prácticas de producción material del espacio. No obstante, para que el modelo se reprodujera mediante pervivencia, incluso después de la crisis de 1982, fueron necesarios nuevos mecanismos ideológicos de reproducción socioespacial. Las siete modernizaciones arquetípicas erigidas durante el ciclo dictatorial chileno $-\mathrm{y}$ que realmente ascienden a más de una docena (Hidalgo et al., 2016)- se encaminaron a garantizar la reproducción de un capitalismo a la chilena (Solimano, 2013), junto con la cooptación financiera de las clases trabajadoras y la instalación de un sistema perpetuo de financiamiento al sector privado desde la privatización de los fondos de pensiones; ejecutándose, junto a lo anterior, el esquilmo a los bienes sociales de consumo colectivo como salud, educación y vivienda, bajo una idea de modernización como dispositivo de privatización de las empresas públicas.

Desde lo anterior, en un segmento significativo en este escenario distópico, asciende la metáfora sobre el cotidiano que Lefebvre denominó como "tu presente es un simulacro" (2007: 33). El Barrio Italia, localizado en la zona central de Santiago de Chile, exhibe condiciones que posibilitarían una descripción del metaespacio propuesto como concepto descriptivo, contestando desde la empiria las comparaciones y metonimias señaladas anteriormente, que no logran identificar el paralelismo de cada trama del espacio.

\section{Metodologías y articulación empírica}

La oralidad, las narrativas y los relatos son lenguajes que hacen emerger no sólo conciencias temporales, sino también espaciales. Las primeras se agrupan en lo que ha sido denominado como el conjunto de los tropos de la metahistoria (White, 1992), cuya materialidad es capaz de ser leída en lo espacial, rezumando flujos simbólicos propios del metaespacio. Para rescatar estas ideologías urbanas, han sido elaborados cinco instrumentos de entrevista breve para la recuperación de experiencias que, desde la narrativa vivencial, posibilitan el acercamiento a las subjetividades de paseantes, propietarios y empleados en el Barrio Italia (Hernández et al., 2010). Estos instrumentos quedaron ordenados como se muestra en el Cuadro 1.

Cada formulario de entrevista contiene cuatro preguntas que, en cada caso y contexto, pretendieron extraer información acerca de las percepciones, cambios, decisiones, experiencias, satisfacción, problemas y características sociales del barrio. La muestra estuvo constituida por diez entrevistados - dos por cada formulario-, bajo una modalidad de muestra no probabilística 


\section{Cuadro 1}

Tipo de formularios aplicados

\begin{tabular}{cl}
\hline Formulario & \multicolumn{1}{c}{ Descripción } \\
\hline 1 & Aplicado a quienes tenían más de diez años viviendo en el barrio. \\
2 & $\begin{array}{l}\text { Aplicado a quienes eran propietarios de un local comercial de baja } \\
\text { escala, es decir, almacenes de abarrotes y quioscos, además de ser } \\
\text { residentes del barrio, que se encontraban realizando dicha actividad } \\
\text { por más de diez años. }\end{array}$ \\
& $\begin{array}{l}\text { Aplicado a quienes eran propietarios de un local comercial de reciente } \\
\text { instalación en el barrio y que se relacionaba con actividades de sectores } \\
\text { en proceso de revitalización. Su antigüedad era entre uno a cinco años } \\
\\
\text { y no necesariamente eran residentes del barrio. } \\
\text { Aplicado a quienes se encontraban trabajando en el barrio y provenían } \\
\text { de otros países. } \\
\text { Aplicado a quienes se encontraban trabajando en el Barrio Italia, } \\
\end{array}$ \\
& ya sea en el comercio u otras actividades.
\end{tabular}

Fuente: Elaboración propia.

combinada, a partir de una muestra compuesta por tres mujeres y siete hombres, ubicados en un rango de edad entre los 18 y 90 años.

El tipo de muestra se justifica en virtud de la necesidad de comprender un concepto (Hernández et al., 2010), que en este caso es el de metaespacio y sus lógicas. Las observaciones, fotografías y entrevistas fueron realizadas entre los días 2 y 15 de enero de 2017.

En términos generales, la muestra tuvo características heterogéneas en lo referido al rango etario e identidad de género de los sujetos. En el Cuadro 2 se indican los detalles de los entrevistados.

En función de la trayectoria de la descripción, unida a que las tramas, polirritmos y ciclos en el espacio urbano no siguen patrones definidos, sino que emergen como rizomas en el metaespacio, el análisis de las narrativas se realizó a partir de la teoría fundamentada. Como proceso analítico que permite ir identificando los hallazgos conforme éstos emergen, la forma de extraer los relatos no es lineal y, teniendo la certeza de su inicio, no es posible determinar dónde finalizarán (Hernández et al., 2010).

Para complementar esta información cualitativa se confeccionó una base de datos con los permisos de funcionamiento comercial ${ }^{6}$ otorgados entre 2010 y 2015 por la Municipalidad de Providencia, donde se ubica el Barrio Italia. Éstos se clasificaron en cinco categorías: alcohol, comercio, industrial,

${ }^{6}$ En Chile se denomina a estos permisos como patentes comerciales, agrupándose distintos rubros del sector servicios. Se utilizará en adelante esta denominación. 


\section{Cuadro 2}

Características etarias de los entrevistados

\begin{tabular}{clc}
\hline Formulario & Edad & Identidad de género \\
\hline 1 & 82 años & Masculino \\
& 46 años & Masculino \\
\hline 2 & 57 años & Masculino \\
& 60 años & Masculino \\
\hline 3 & 19 años & Femenino \\
& 32 años & Femenino \\
\hline 4 & 42 años & Masculino \\
& 26 años & Masculino \\
\hline 5 & 48 años & Masculino \\
& 20 años & Femenino
\end{tabular}

Fuente: Elaboración propia.

profesional y propaganda. Tales registros, que ascienden a 1065 , fueron procesados en ArcGIS 10.3, desde el módulo geocoding. Finalmente, para verificar la evolución sociodemográfica del Barrio Italia, se utilizaron los censos de población 1992, 2002 y 2012, con el software Redatam. La síntesis de estos procesos se aprecia en el Esquema 1.

\section{Hacia una lectura del sujeto en el metaespacio del neoliberalismo}

La configuración de la experiencia subjetiva sobre un entorno determinado responde a un conjunto de elementos y factores que actúan sobre el cómo representar lo espacial. La zona del Barrio Italia, localizada en el área central de Santiago de Chile, reúne determinadas excepcionalidades que han fortalecido su rol como lugar de interés turístico y escena de culturas manifestadas como alternativas. Contradictoriamente, la primera rugosidad que emerge en su lectura es la escasa presencia de población residente en las principales manzanas.

Las calles Italia y Condell presentan cantidades muy menores de población -entre treinta y cien residentes-, lo que altera cualquier definición de barrio como unidad mínima espacial de un hábitat sobre el que se construyen nexos de comunidad, colaboración e historia en común (Gravano, 2005). En el Mapa 1 se refleja, con base en los últimos datos censales disponibles, una concentración hacia las laterales de las manzanas que recorren las calles 


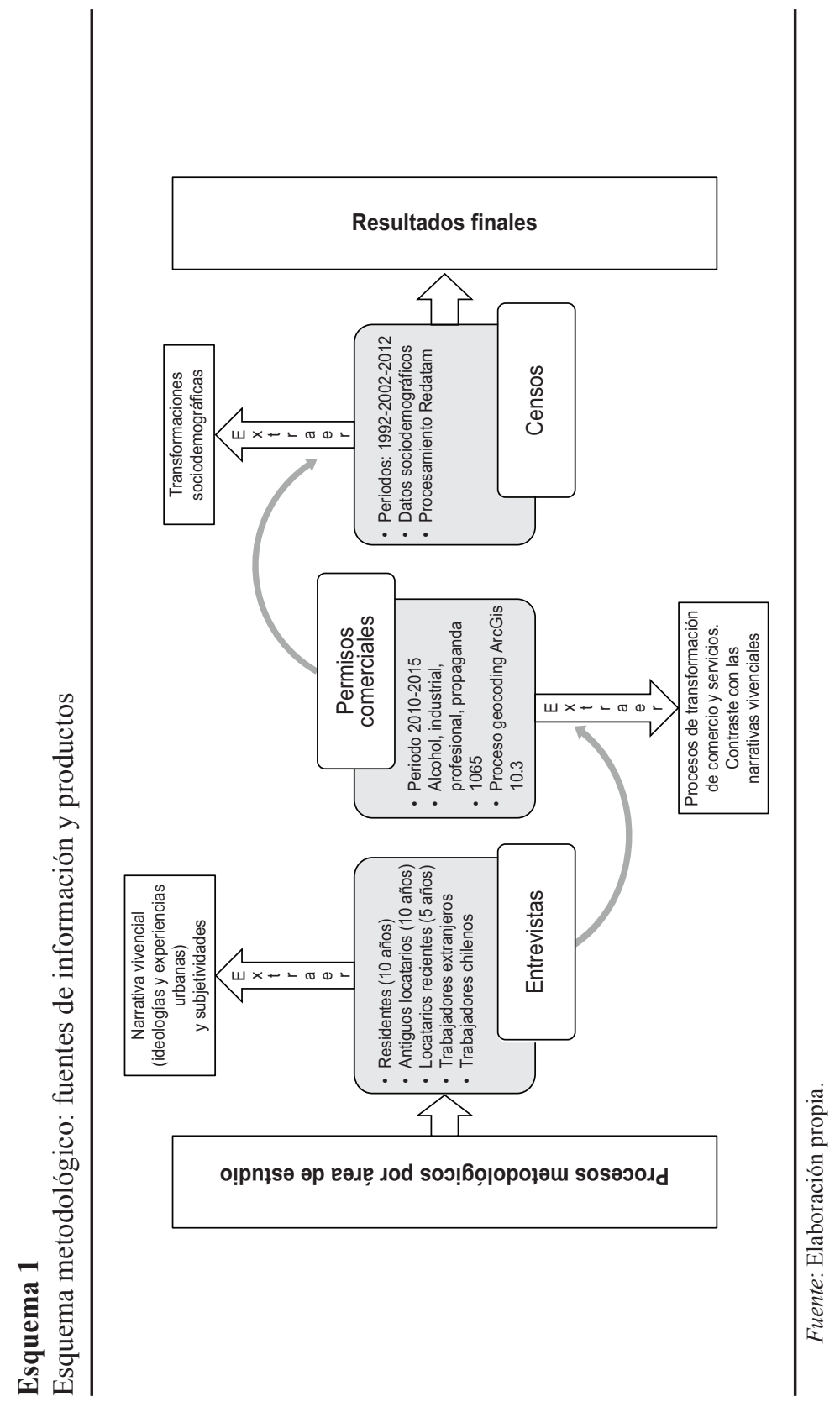




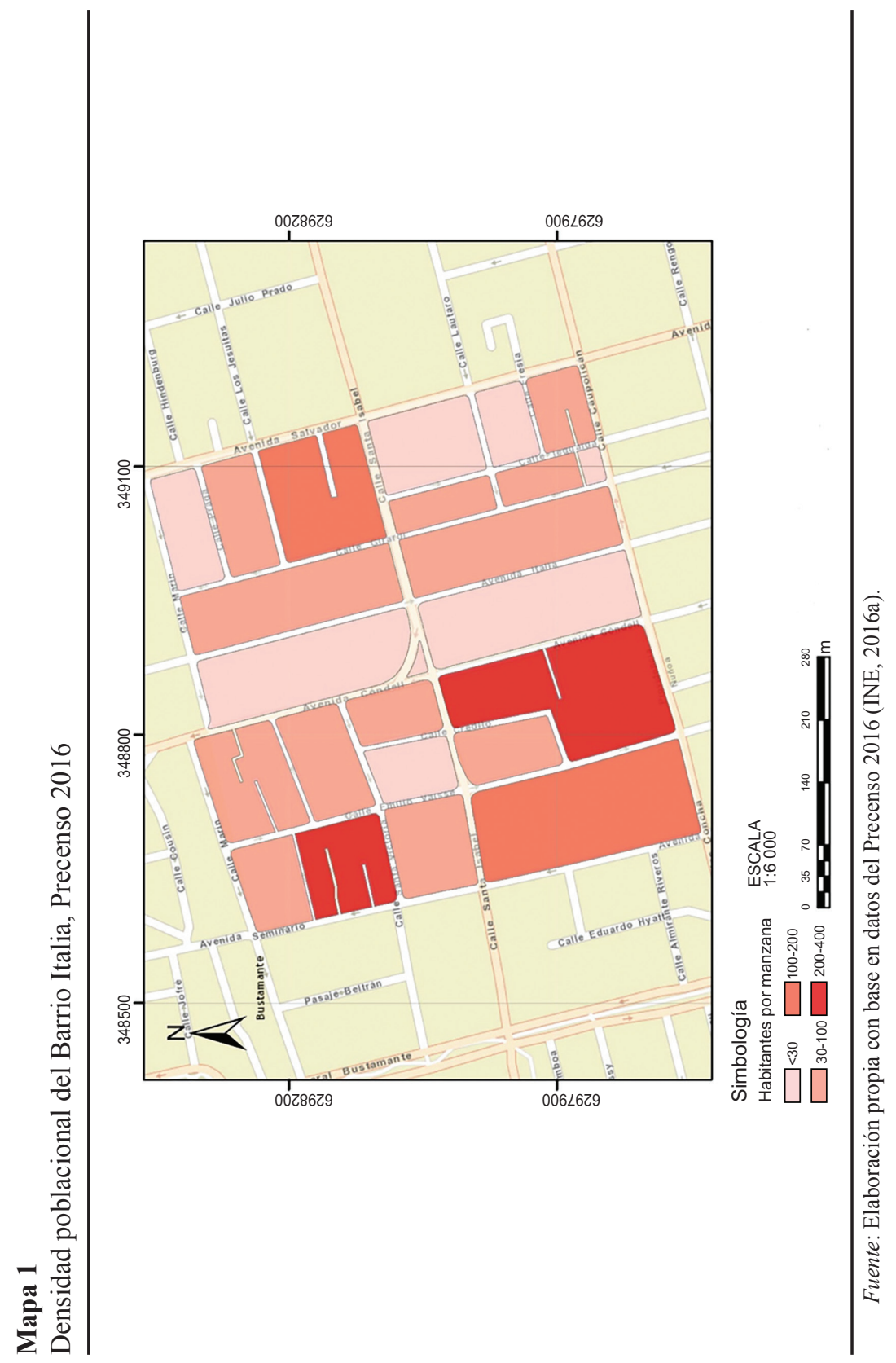


indicadas, caracterizando el cambio de vocación residencial hacia uno comercial y turístico en la actualidad.

Esta tendencia es contraria al comportamiento demográfico e inmobiliario del municipio de Providencia. Emplazada en lo inmediato a la zona central de la capital chilena, está en el interés de desarrolladores inmobiliarios de alto estándar, quienes ofertan residencias nuevas y cercanas al barrio, cuyos valores se aproximan a los USD $280000 .^{7}$

Sin embargo, dentro del Barrio Italia la presencia de alquileres con fines comerciales es masiva. Para diciembre de 2016 la oferta para estos productos alcanzaba las 15 unidades, promediando un costo de USD 1875 por mes de uso. Por otro lado, las viviendas en venta, todas usadas, anotan un registro menor, identificándose sólo una unidad dentro del área, cuyo valor asciende a los USD $833000 .{ }^{8}$ Esto explicaría la reducción de población residencial en favor del loteo masivo de unidades habitacionales con objeto de una densificada comercialización de éstos, arrojando incluso una sostenida disminución de la habitación residente respecto al total de la comuna en relación a los tres últimos censos, contabilizados desde 1990 en adelante. Esto aparece expresado en la Gráfica 1.

Las condiciones materiales impactan sobre las características subjetivas del barrio. Aquí la producción material del espacio no es un proceso aleatorio a su reconfiguración; es, más bien, adyacente por sobre su materia y fondo.

Por otro lado, las condiciones de expolio inmobiliario definidas con anterioridad, inhiben las opciones de tipificar al barrio como zona gentrificada, puesto que no ha acontecido un recambio de habitantes, sino que ha operado un alza de los precios en torno a su valor de cambio, despojando del barrio a sus habitantes iniciales. Así, esta descripción desde el metaespacio va en la dirección de lo subjetivo, donde las condiciones materiales de expoliación son espacialmente fijas, al mismo tiempo las subjetivas son móviles.

La descripción de Lefebvre utilizada como base metodológica permite considerar esta dualidad en el proceso de expoliación. Como se revisa más adelante, las razones neoliberales desarrolladas en párrafos anteriores producen un valor de expectativa en el cambio de uso del suelo urbano, impactando además en las formas de construcción dinámicas de un barrio que no cesa en sus transformaciones.

${ }^{7}$ Es el caso del edificio Porta Italia, ubicado a cuatro calles del inicio del Barrio Italia. Aun sin estar en el centro del mismo, el operador inmobiliario se esmera en reproducir esquinas y tiendas emblemáticas de la zona. La oferta actual puede revisarse en la web http://www. portaitalia.cl (29 de enero de 2017).

${ }^{8}$ Los valores residenciales y comerciales corresponden a la oferta catastrada en los portales de compraventa y alquiler para bienes raíces Portal Inmobiliario, cuyo enlace web es: http://www.portalinmobiliario.cl (5 de enero de 2017). 


\section{Gráfica 1}

Evolución de la población Providencia-Barrio Italia

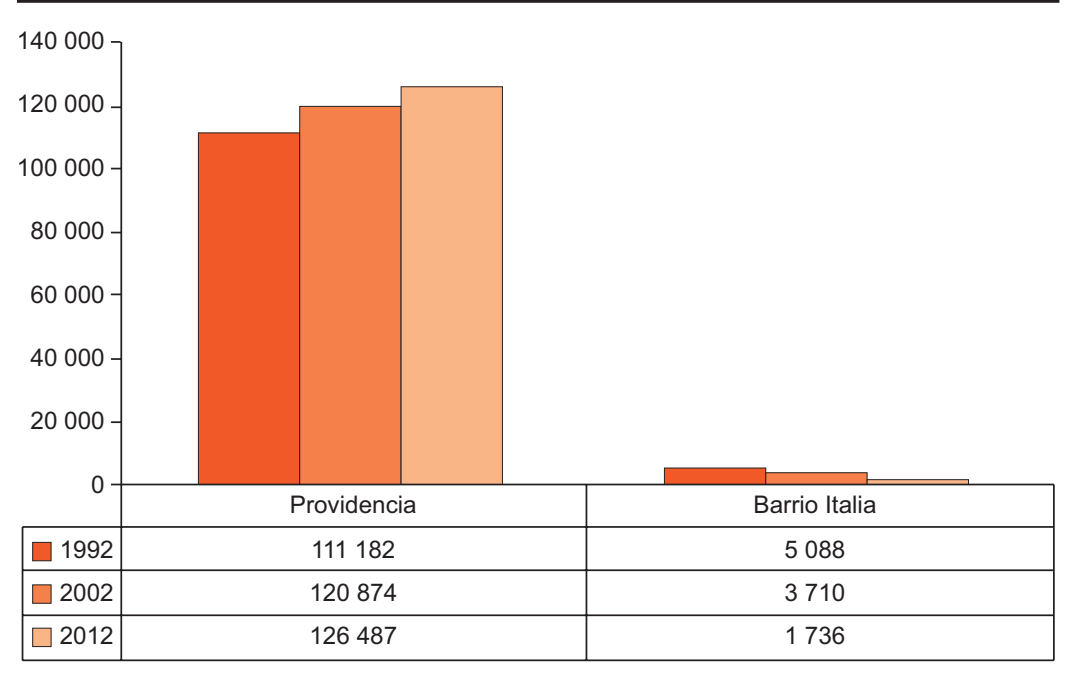

Fuente: Elaboración propia con base en datos actualizados para 2016 del Instituto Nacional de Estadísticas (INE, 2016b).

\section{Ciclos espaciales}

El interés comercial por participar de los ciclos espaciales del barrio es tal, que los propietarios primigenios han cedido al avance del mercado, vendiendo sus propiedades y entregándolas a nuevos emprendimientos comerciales. Rafael, un residente desde finales de la década de 1970, indica que la salida de sus vecinos ha sido progresiva e irreversible:

Desde 1978, hasta hace por lo menos diez años atrás [2007], el barrio era prácticamente residencial. Vivía gente, tenía vecinos; al lado de mi casa había un colegio que duró hasta el año 1990, llamado Samuel Lillo. Después, la propietaria quedó viuda y se fue. Se puso una fábrica de señaléticas acrílicas, que estuvo hasta hace tres o cuatro años. El dueño de esta empresa vendió y pusieron una oficina de plotter. Después de esto, hace como dos años [2015] el cabro [dependiente] vendió y se instaló una venta de muebles [...] El barrio era residencial hasta hace veinte años atrás [1997] y muchos vecinos se fueron, otros murieron y prácticamente donde estamos viviendo con mi mamá somos los últimos de la cuadra. Nosotros también estamos vendiendo para irnos de aquí a dos años [RP. P3, 2017]. 
Los ciclos espaciales con que Lefebvre trabaja las descripciones en ritmanálisis explican las transformaciones advertidas por el entrevistado. El traslado de una aptitud residencial hacia otra industrial, para luego avanzar hacia la especificidad de un comercio exclusivo, manifiesta también el impacto neoliberal en las dinámicas de consumo, las que no sólo se reflejan en la conversión de usos sobre la propiedad en el barrio, sino que responden al agotamiento de modelos de producción de renta situada, donde el plusvalor eventual marca el sello con que el ciclo espacial modela la percepción de los sujetos sobre el entorno.

El signo de este movimiento lefebvriano se plasma en la opinión de otro residente. Marco, con 82 años y una vida realizada en el Barrio Italia, expresa que tanto las calles como los nuevos negocios pertenecen a modos de vida disímiles, convirtiéndose en otro lugar, pero sobre el mismo polígono:

La cuestión comercial a nivel de bazar [comercio al detalle de menor escala] se ha ido eliminando. Ahora hay que ir al supermercado o al mall $[\ldots]$ Hay gente que llega a poner su taller, ya no llegan familias. Aquí al costado hay un pasaje donde hay 14 casas, con muy pocas familias. Allí donde está el edificio, antes había un local llamado "La Preferida", hace 15 años más menos, y la gente que llega a esos edificios no comparte con nosotros [MA. P3, 2017].

La disolución de los vínculos entre pares, el sentido de barrio como lo indica Ariel Gravano (2005), decae con el ingreso de las especialidades comerciales de la zona. La mutación hacia talleres, mueblerías o bares exclusivos, quiebra el ciclo espacial de la comunidad, instalándose la idea de barrio como alternativa de negocios dentro de un circuito dedicado a un grupo específico de personas. Las Fotografías 1 y 2 ilustran dicha condición de otredad, con la que el Barrio Italia ha buscado seducir a sus paseantes a partir de un nuevo ciclo espacial.

Los ciclos espaciales presentes evidencian la superposición de temporalidades inconexas, aun cuando entre ellas exista un reconocimiento del otro. Esta idea se opone a la lógica de proximidad espacial, donde la topología explicaría la relación entre dos fenómenos. Aquí, si bien conviven dos ciclos, las relaciones entre ellos no son representativas de un barrio o comunidad. 


\section{Fotografía 1}

Ciclos espaciales del Barrio Italia. Cartelera de servicios alternativos ofrecidos por los nuevos habitantes del barrio

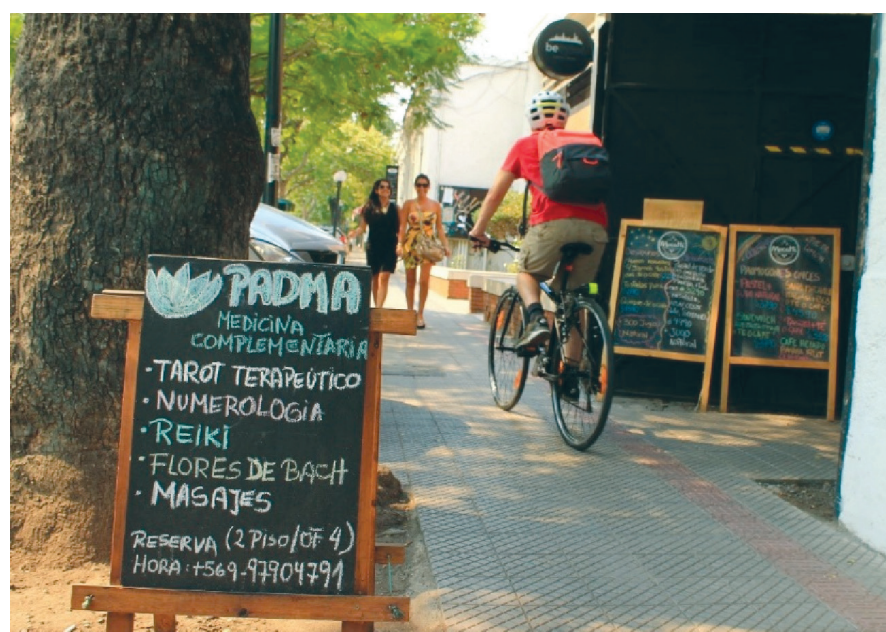

Fuente: Fotografía de Hans Fernández (enero de 2017).

\section{Fotografía 2}

Persistencia de un anacrónico cité*

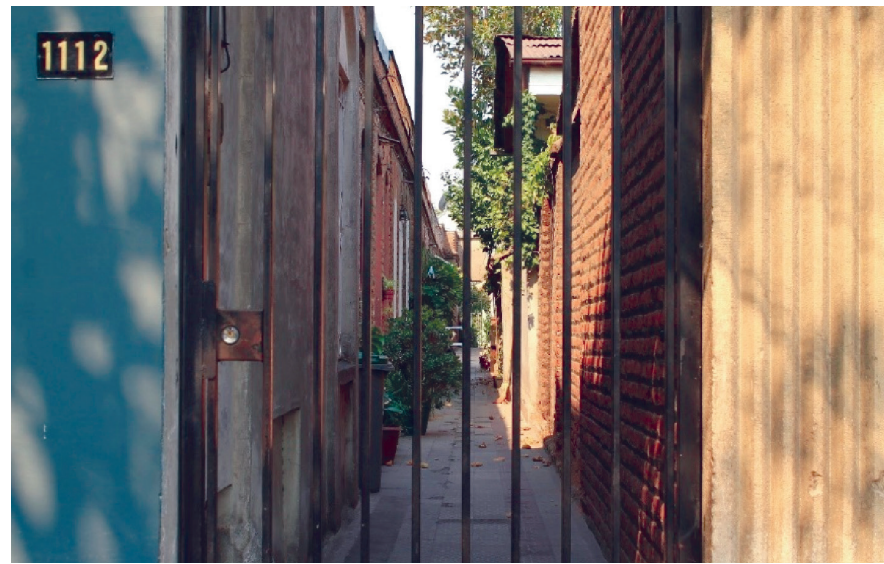

* Señalado por Marco en su entrevista. A pesar de ubicarse a escasos metros, ambos puntos no se asemejan en absoluto dentro del actual ciclo del barrio.

Fuente: Fotografía de Hans Fernández, enero de 2017. 


\section{Polirritmicidad}

La idea sobre un barrio alternativo emerge con fuerza desde las diferentes tramas espacio-temporales desarrolladas en el área estudiada. En una publicación anterior de Schlack y Turnbull (2009) se describe al Barrio Italia como entidad colonizada por artistas locales, quienes han instalado talleres en las antiguas residencias, dando así una idea de gentrificación basada en la llegada de estos nuevos habitantes y su consecuente elitización.

La inclusión de una clase media trabajadora en el barrio sucumbe ante los altos valores del suelo, recogiéndose a las escasas densificaciones en altura presentes. Aquí se manifiesta una nueva tensión hacia los propietarios y dependientes originales, quienes desarrollan actividades lejanas al toque chick de este nuevo ciclo y su reproducción simbólica, algo que los autores denominan como efecto bola de nieve, arrastrando al barrio hacia una homogeneidad alternativa, pero sintonizada con las dinámicas del capital y la inversión (Schlack y Turnbull, 2009: 4-5).

Ciertamente, el neoliberalismo como ideología concibe una alienación de los sujetos manifestada en la obliteración del otro que, aun caminando por la misma vereda que los artistas del Barrio Italia, pertenece a una ritmicidad diferente, de ocupaciones esquilmadas y explotación salarial, propias del marco socioeconómico trazado en el país en los últimos decenios. Estos polirritmos se aprecian en las actividades que los inmigrantes desarrollan en bares y restaurantes del barrio, quienes, sin toparse con artistas o propietarios, aprovechan la boga del lugar para acceder a un trabajo remunerado.

Procedente de Haití, Dimitry encontró una plaza como carpintero en uno de los talleres de restauración que existen en el barrio hace más de dos décadas. Estos negocios corresponden a los únicos establecimientos permanentes de la zona. Su ciclo ha sido más largo que el resto y lo demuestran al ocupar las veredas públicas con mesas, sillas, pianos u otras antigüedades perseguidas por compradores pertenecientes a las clases acomodadas de Santiago. Para Dimitry, su trabajo es ideal: "lo encontré andando, buscando a pie [...] Y decidí trabajar acá porque sé hacer este oficio de carpintería" (D. P2, 2017). Véase la Fotografía 3.

Las tramas conviven, pero no se tocan. El metaespacio explica distintas realidades, donde la alienación de los sujetos va de la mano con las formas de acumulación capitalista actual. Con la emergencia del barrio como un lugar exclusivo, la cercanía pasa a ser una trampa en las interpretaciones sobre lo que se entiende como tal. Topológicamente, cada negocio, trabajador, propietario o paseante, participa de su única experiencia, sin encontrarse espacialmente. Los polirritmos que Lefebvre desarrolla en su 


\section{Fotografía 3}

Uso del espacio público por mueblistas en calle Caupolicán, Barrio Italia

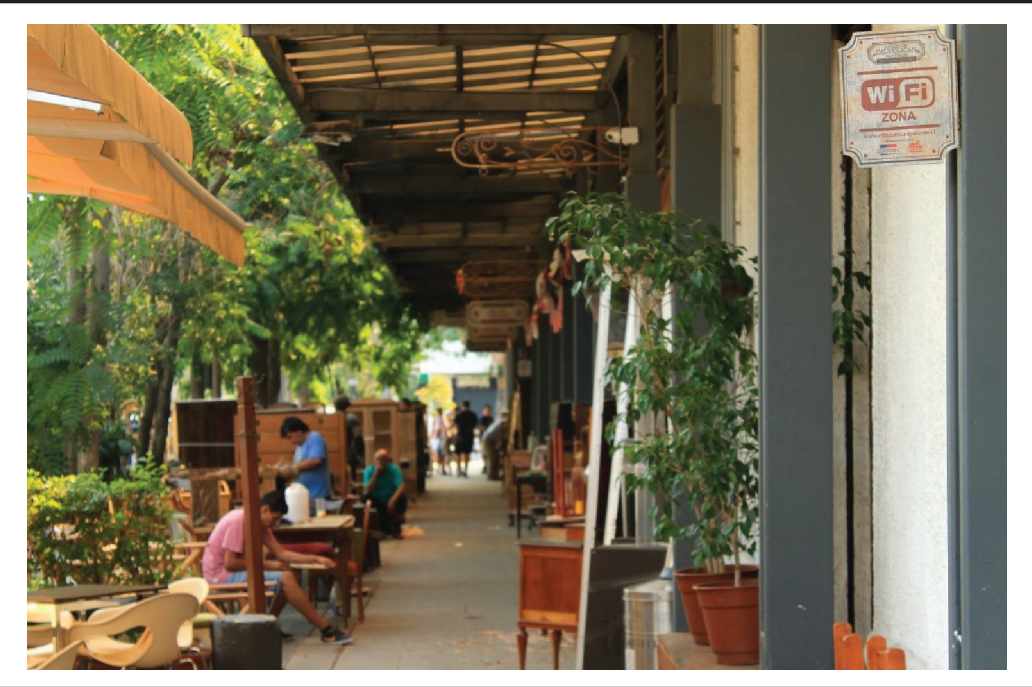

Fuente: Fotografía de Hans Fernández, enero de 2017.

análisis (2007) emergen desde las prácticas alienadas de los usuarios, que al mismo tiempo se adaptan a cada ciclo. Para los mueblistas, el tiempo está detenido y el espacio lo viven como fijo, no así para los otros rubros comerciales.

Otro ritmo es el observado en los dependientes de pequeños mercados o tiendas de abarrotes en la zona. Guillermo, propietario de uno de estos negocios desde hace cuarenta años, explica la necesidad de seguir los ritmos y cambios que el barrio impone a sus locatarios. De cierta forma, lo que espera es adaptarse a las nuevas demandas y así no colapsar ante sus nuevos usuarios:

No he tenido problemas con otro tipo de comercio, pero pienso que nosotros vamos a desaparecer con el tiempo si no innovamos. Menos mal que nosotros somos propietarios; la persona que arrienda tiene que venir con una proyección, con algo más moderno. Los negocios que han llegado al Barrio Italia son todos modernos [GC. P2, 2017].

La modernización aludida por Guillermo es la que marca el compás de los polirritmos descritos. Zulema, que alquila uno de los pequeños locales 
ubicados en las nuevas galerías de la zona, expresa desconfianza respecto a la capacidad de perpetuarse para las nuevas formas del barrio. Las tramas espacio-temporales del paseante son indeterminadas, y cooptan desde el consumo la idea del espacio cosmopolita que busca erigirse como identidad de barrio. Ante la consulta por lo que viene para el sector, la entrevistada expresa sus temores:

Tengo mi taller donde fabrico mis productos muy cerca de acá, como a dos cuadras, y además lo abrí por la temporada alta [...] Depende del día, pero en la semana viene mucho extranjero, mayoritariamente argentinos y otros de habla inglesa [...] El cliente chileno es un cliente joven que tiene poder adquisitivo [...] Pienso que, si sigue así, no sé si va a seguir como antes. Antes había mucho público, era mucha venta, pero como no se ha reinventado, los precios están caros, los arriendos son caros y hace que tus productos sean caros; la gente viene de paseo, pero no como a comprar [Z. P2-3, 2017].

¿Qué alternativas de encuentro pueden existir en un espacio tan heterogéneo en sus ritmos y tramas? El metaespacio como dispositivo descriptivo permite explorar los ciclos y polirritmos de unidades contradictorias como Barrio Italia desde sus agentes, ocupaciones y entornos. Sobre él se producen los artefactos espaciales que hacen de la zona un lugar particular. Zulema descree de ellas, suponiendo que su otredad es, al mismo tiempo, la némesis del modelo de negocios instalado. La producción espacial como acción pura del neoliberalismo cobra también sus víctimas.

\section{Ruidos y murmullos}

Lefebvre tipifica como ruidos y murmullos a las disonancias producidas por los paseantes en Rambuteau, colocando a los turistas como constructores simbólicos de las experiencias de sus ocupantes laborales o residenciales (2007: 32). La acogida a los turistas representa el valor de uso que posee el Barrio Italia para este ciclo. Ellos son quienes dan significado al entorno, simbolizando la modernidad que la zona ostenta hacia sus locatarios y trabajadores.

Valentina, quien atiende uno de los restaurantes, aporta un ruido tenaz sobre las transformaciones últimas del barrio. Si bien el experimento de producción exclusiva de un espacio alternativo ha funcionado, también acoge a otros sujetos, quienes no forman parte de los propósitos iniciales para la zona: 
Lo que he notado es un cambio social, ya que cerca de acá he notado muchos haitianos y antes veía puros turistas por acá, y gente como más bonita; ahora se ve como de todo, ahora hay harta variedad para elegir, acá al lado hay un minimarket y este local es algo totalmente distinto (jugos naturales y productos no procesados), hay mucha oferta a nivel comercial [V. P3, 2017].

El juicio de Valentina pasa por encima de las políticas de inclusión social y de género promovidas por la saliente alcaldesa Josefina Errázuriz, cuyo mandato, finalizado hace pocos meses, buscó ocuparse de evitar otros ruidos, limitando los horarios de funcionamiento nocturno, esperando así acoger las demandas de los vecinos residentes, de los cuales pocos quedan en el barrio. Las nuevas galerías proponen espacios de murmullo. La diversidad de sus locales, además de una densificada posición para aprovechar las bondades comerciales del barrio, ilustran también la demanda por ocupaciones sobre negocios que podrían ser efímeros, bajo la siempre compleja impronta de los ciclos de inversión y reconversión de unidades territoriales como ésta. Las Fotografías 4 y 5 expresan algo más allá de una fachada sofisticada: manifiestan también la voracidad de los empleos requeridos para el sostén de la reproducción espacial del Barrio Italia.

\section{Fotografía 4}

Una de las galerías del Barrio Italia, Providencia (calles Italia y Condell)*

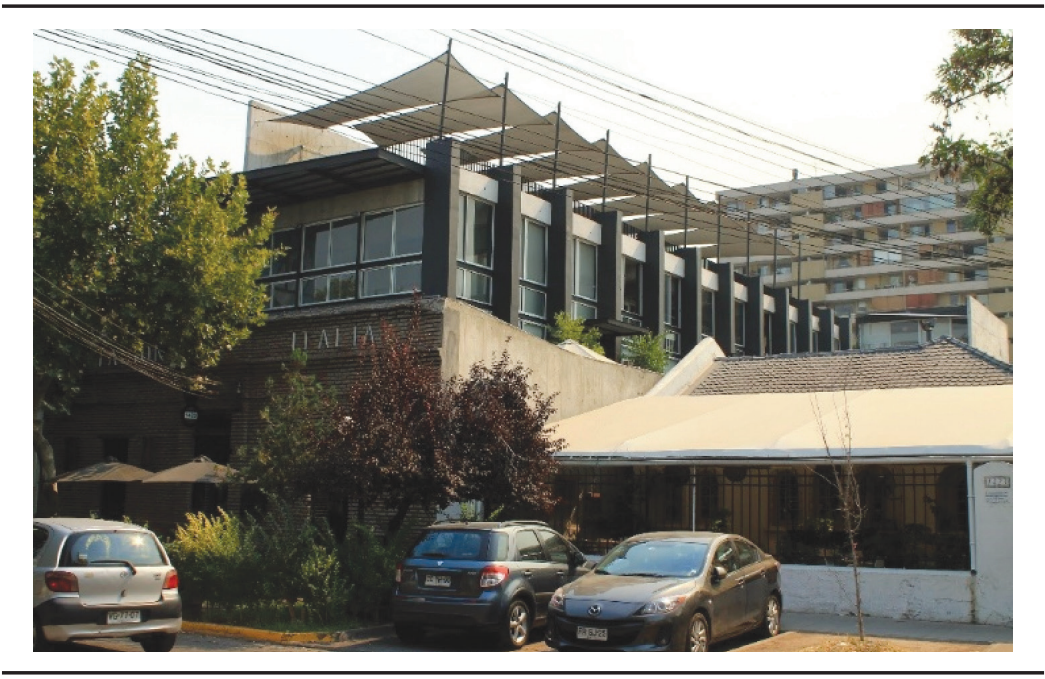

* La adaptación de fachada se respeta para no generar ruidos en el barrio.

Fuente: Fotografía de Hans Fernández, enero de 2017. 


\section{Fotografía 5}

Galerías del Barrio Italia, Providencia*

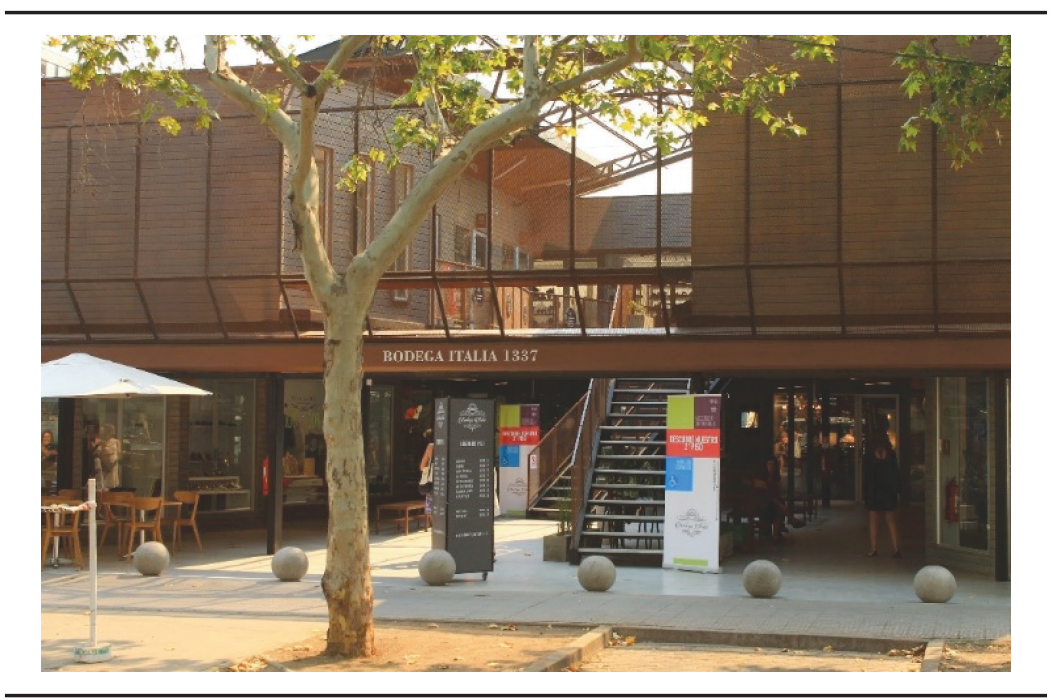

* Se destruyó la fachada anterior y se impuso una nueva, moderna y murmurante. Fuente: Fotografía de Hans Fernández, enero de 2017.

\section{¿Por qué no hay tal gentrificación en Barrio Italia? Una respuesta desde el metaespacio}

La ausencia de un recambio de población, sumado a la pérdida de aptitud residencial para un barrio actualmente dedicado al turismo y al comercio, impactan sobre las evidencias aportadas en la sección anterior. La población ha disminuido sostenidamente y el aumento de las patentes comerciales destaca interesantes ciclos de expansión y contracción. Así como las bases del ritmanálisis han sido ejecutadas sobre paseantes, residentes, locatarios y trabajadores, pueden también aportar en la relación de estas evidencias con la categoría metaespacial que ha sido desarrollada. El Mapa 2 caracteriza estos ciclos dentro del Barrio Italia.

Los datos aportados en la cartografía permiten construir una trama de ciclos sobre el Barrio Italia, que es advertida por los entrevistados al afirmar que la tendencia de la zona apunta hacia lo comercial por sobre cualquier otra especialidad territorial. Pero yacen junto a esto otras condiciones de tipo simbólico y material dentro del contexto urbano neoliberal imperante en Chile: 


\section{Mapa 2}

Comportamiento espacial de las patentes comerciales, Barrio Italia 2010-2015
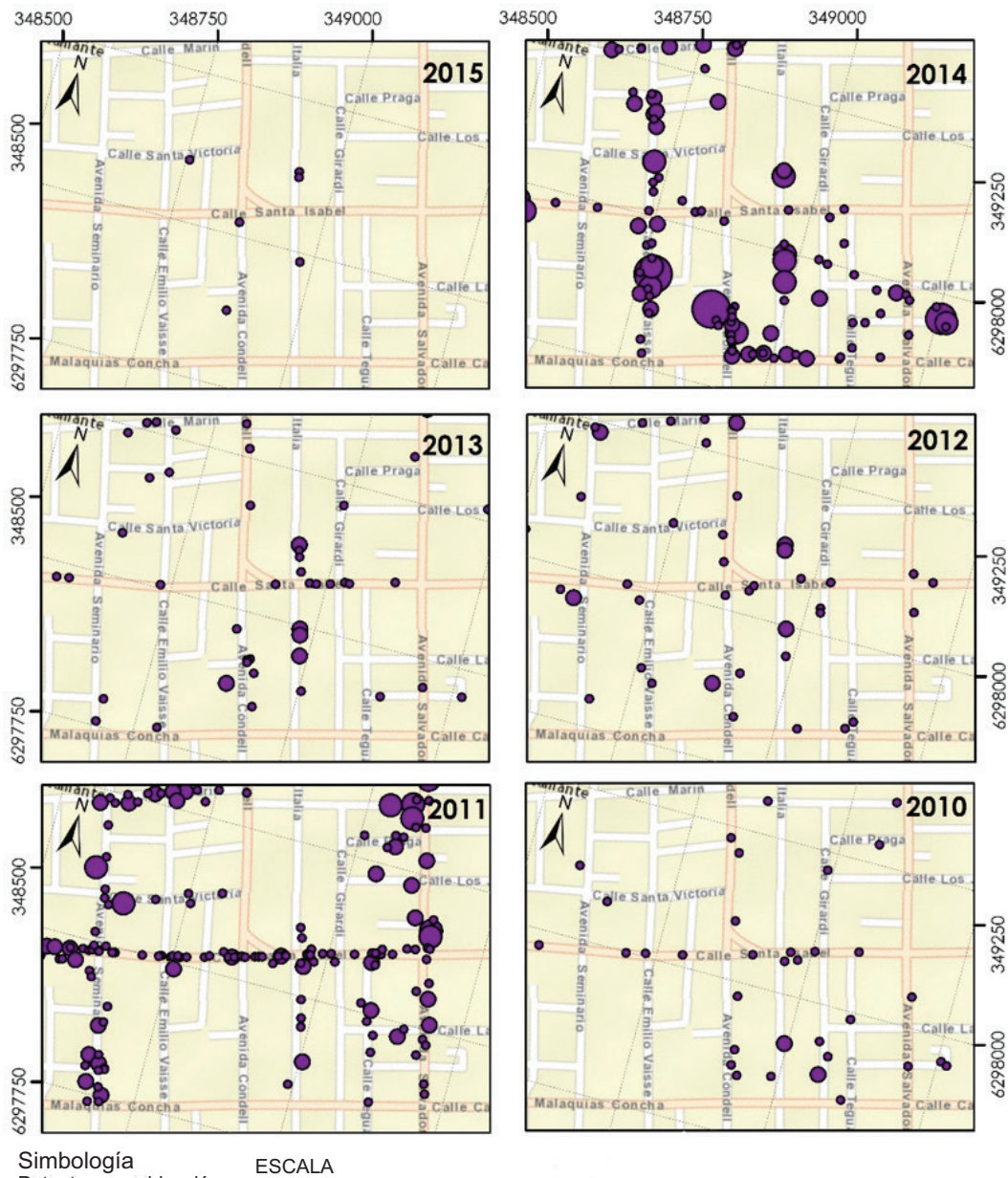

Patentes por ubicación: $\quad$ 1:10 000
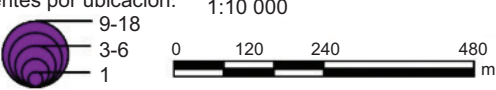

Fuente: Elaboración propia con base en Municipalidad de Providencia, 2016. 
Periodo 2010. A inicios de la segunda década del nuevo siglo, el otorgamiento de patentes comerciales fijó ciertos puntos de interés, situando a la avenida Italia como eje de gravedad espacial del polígono conformado por las calles Girardi, Caupolicán, Condell y Marín. Esta situación articuló un primer ciclo, donde la población, que venía descendiendo desde 1992 en adelante, terminó por reducirse a un mínimo hacia los años siguientes. Se entregaron 59 patentes.

Periodo 2011. Ciclo explosivo del Barrio Italia. Tal como plantea Rafael, una zona residencial con presencia de pequeñas y medianas empresas -PYMES- giró hacia una faceta comercial diversificada, tomando la impronta patrimonialista que operase sobre otros sectores de Santiago, donde la historia o la construcción de la memoria de los barrios terminó por golpear ascendentemente las plusvalías del suelo. Con ello, y mirando la captura del censo de 2012, sobre el barrio la gentrificación fue imposible, puesto que la población primigenia no sufrió recambio alguno, sólo se redujo en relación con el perfeccionamiento espacial de una zona donde convergen diversos intereses. Ese año el barrio recibió 326 patentes comerciales.

Periodo 2012. Año de elecciones municipales y, ante un inminente cambio de alcalde, las patentes comerciales se contrajeron. Es derrotado Cristián Labbé, militante de Renovación Nacional y excoronel de ejército acusado por violaciones a los derechos humanos durante la dictadura de Pinochet. Después de veinte años a la cabeza de la comuna, asumió la candidata de las juntas de vecinos progresistas autodenominadas como ciudadanas de Providencia, Josefa Errázuriz, en diciembre de 2012. Bajo este marco político, el patrón de concentración sobre el polígono interior y el eje gravitatorio señalado se acusó con intensidad, al mismo tiempo que los bordes exteriores también sufrieron una colonización comercial. La situación política fue parte del ciclo que sufrió el barrio, donde ante la incertidumbre del eventual rumbo que podría tener una nueva administración comunal, el capital aguardó expectante. Sólo se cursaron 86 patentes.

Periodo 2013. La nueva administración municipal continuó con la lógica de operaciones heredada y, para el año indicado, no se apreciaron mayores cambios. Sólo una situación: en la calle Italia la densificación de patentes comerciales sobre una dirección aumentó considerablemente. Si para 2010 esta situación era incipiente, hacia 2015 la tendencia fue generar galerías, pasajes o casonas subdivididas con patio común, donde se instalaron distintos tipos de negocio. Esto fue refrendado en las entrevistas presentadas, y se aprecia en las Fotografías 4 y 5. Esta densificación es la que convertirá al Barrio Italia en una zona especializada de tránsito comercial, abandonan- 
do su anterior vocación residencial. El ciclo de 2013 es el punto de quiebre hacia la actualidad, con 104 patentes.

Periodo 2014. La densificación de patentes estalló, diseminándose por las distintas calles interiores y exteriores al barrio. Ese año, con 476 patentes otorgadas, marcó el inicio de la consolidación de la zona sobre este modelo de negocios. Las calles Italia y Condell quedaron unidas por los corredores interiores de las galerías, que atraviesan las manzanas de una vía a la otra. Para la segunda mitad de ese año aconteció una situación no advertida por los locatarios y paseantes: la administración de Josefa Errázuriz propuso una ordenanza municipal que restringió el funcionamiento de recintos expendedores de alcohol. ${ }^{9}$ Este punto detona un complejo escenario de controversia, donde los paseantes del Barrio Italia se encontraron con una norma que restringía el flujo de sus actividades de ocio, e imponía a los propietarios de las patentes comerciales cubrir las demandas aspiradas de esparcimiento. La poca aceptación de estas medidas provocó la derogación de la prohibición de operaciones para diciembre del mismo año, cuando se fijó un horario de cierre progresivo para la semana, considerando como tope máximo las cuatro de la mañana en las jornadas de jueves a sábado. ${ }^{10}$ La medida restrictiva había durado dos meses.

Periodo 2015. A pesar de la rápida reacción política del municipio, el efecto hacia la obtención de patentes comerciales era irreversible. El ciclo 2015 anotó sólo 16 registros comerciales, reduciendo al mínimo los pingües guarismos anteriores. El Barrio Italia y la posición de locatarios y residentes sobre los horarios de funcionamiento configuraron una frontera interna entre ellos. Estos últimos, reducidos en presencia, se aglomeraron en los nuevos edificios construidos en las zonas limítrofes del barrio, que buscaban redituar de la estética simbólica del lugar. Una nueva población apareció, pero no dentro del polígono interior ni de su eje gravitacional. Se localizaron en las orillas, esperando recoger el rebalse del encanto espacial que se respira en el Barrio Italia (véase la Fotografía 6).

Todo espacio tiene sus sobrevivientes. A las categorías descritas desde el ritmanálisis, se inhiben locatarios anteriores a las transformaciones del barrio. Talleres mecánicos y mueblistas no participan de los cambios descritos, y sus actividades son fijas ante el escenario líquido que experimenta el resto. Los primeros han logrado adaptarse, eso sí, al tipo de público que concurre al área en cuestión, apuntando a vehículos de alto costo y prestaciones. Leopoldo, con

9 Ordenanza Municipal núm. 132, 7 de octubre de 2014, Ilustre Municipalidad de Providencia, Chile.

${ }^{10}$ Ordenanza Municipal núm. 137, 10 de diciembre de 2014, Ilustre Municipalidad de Providencia, Chile.

Estudios Demográficos y Urbanos, vol. 33, núm. 1 (97), 2018, pp. 79-110 ISSN 0186-7210; e-ISSN 2448-6515; doi: http://dx.doi.org/10.24201/edu.v33i1.1728 


\section{Fotografía 6}

Edificios residenciales en la esquina de las calles Caupolicán

y Emilio Vaisse*

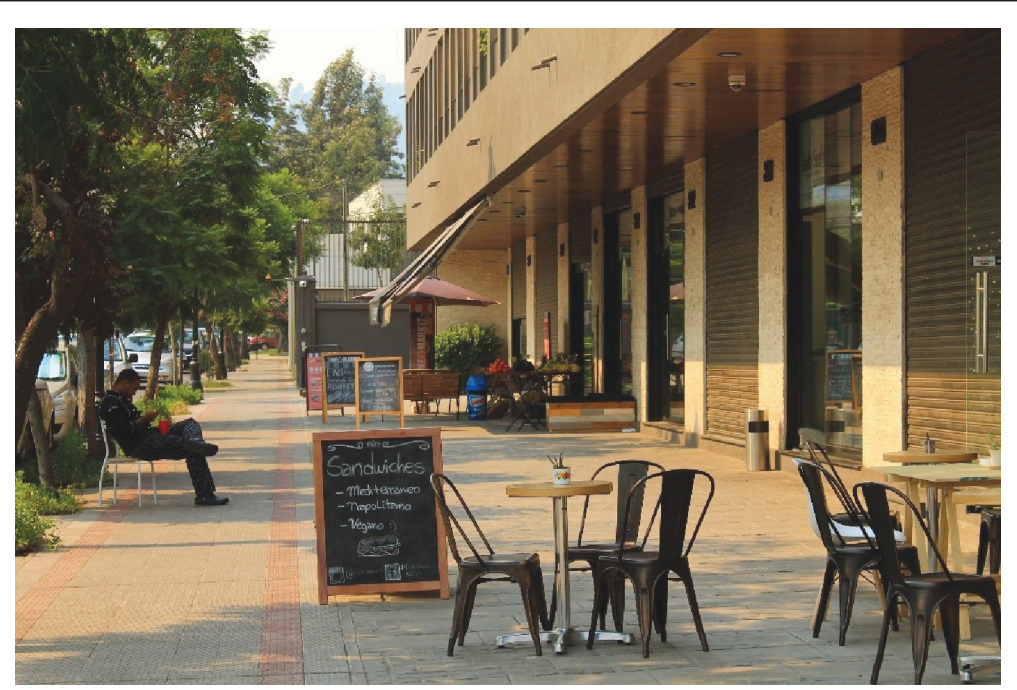

* La integración vertical de lo residencial junto a lo comercial hace de estos conjuntos habitacionales una oportunidad para la funcionalidad del barrio. Sin embargo, esto acontece fuera de él. Por más que sus habitantes adquiriesen la imagen de la zona, no pertenecen a ella.

Fuente: Fotografía de Hans Fernández, enero de 2017.

cuarenta años trabajando como mecánico, reconoce desde su ocupación el cambio que el Barrio Italia ha vivido en los últimos años:

En general el cambio ha sido muy profundo, porque antes este sector no era muy comercial, habian muy pocas tiendas o almacenes. Garajes siempre ha habido bastantes, pero normalmente no existía mucho comercio, ahora la cantidad de comercio es radical [...] A nivel social, llega generalmente gente del barrio alto, el cambio social ha sido bien radical [...] A nivel urbano también, la plusvalía ha crecido bastante, los precios de ventas y de arriendos han crecido enormemente este último tiempo [LC, P3, 2017].

Desde estas apreciaciones, la idea de gentrificación se desmorona. Primero, porque la condición de sitio y su especialización comercial no consideran como agente relevante al propietario residencial en las zonas de mayor interés para el barrio. Las edificaciones son exteriores al polígono interior, a lo que se suma el comportamiento de las patentes comerciales y la reduc- 
ción de población para las manzanas interiores. No existió recambio de población, aunque sí se aprecia un notorio esquilmo del recurso suelo, donde la maximización de la densidad aparece como el medio más operativo hacia la producción de espacio atractivo en lo simbólico y lo financiero.

Pero lo más relevante es lo segundo. Al no poseer una comunidad de propietarios consolidada, que sea constructora de barrio como unidad espacial simbiótica y solidaria, se aprecia una zona de reproducción espacial alienada, donde las relaciones humanas transitan entre las distintas tramas espacio-temporales que los ciclos comerciales ofrecen para paseantes y trabajadores. Entonces, esta idea de gentrificación positiva, donde una determinada unidad espacial sería rescatada por grupos de artistas o nuevos propietarios de clase privilegiada en lo político y económico, es desahuciada en vista a los antecedentes aquí recogidos.

El metaespacio, por tanto, logra evidenciar lo que oculta el proceso de especialización del barrio, al que le queda cómoda una idea de gentrificación que dialoga con cierta efectividad hacia los agentes inmobiliarios, quienes comprenden en esta categoría una idea de integración social. Este último plano es impracticable en las calles que han sido descritas, puesto que ha sido configurado simbólicamente para ser una alienación particularizada para quienes pueden comprenderlo, y no para el corriente de la población. Tal como decía Valentina, es para la "gente linda".

\section{Notas para el cierre}

Los elementos aquí trabajados, tal como se plantea al inicio del escrito, han pretendido ser abordados desde el activismo académico. Esto, más que una inquisición intelectual, espera aportar como actitud hacia la información crítica, lectura y descripción de aquellos escenarios en los cuales el neoliberalismo espacial y los modos de coaptación del lenguaje operan en distintas dimensiones. Lo económico y lo político en concomitancia, modelan el espacio y determinan las fijaciones que desde ello se reproducen en lo subjetivo. La propuesta tomada desde Lefebvre ha pretendido aquello, toda vez que lo desarrollado desde el ritmanálisis es un diálogo entre la dinámica de un barrio y las personas que en el cotidiano recorren sus tramas.

Siguiendo lo anterior, y a modo de cierre para este trabajo, se exponen las siguientes ideas:

1. A pesar de manifestarse el Barrio Italia como un espacio distinto dentro de la ciudad, lo que puede verificarse en las entrevistas, esto no lo enajena de la regulación neoliberal y los dispositivos de control de las agen- 
cias públicas. El hecho que la municipalidad interviniese sobre los horarios de funcionamiento, para luego derogar la resolución, explica la vigencia de lo público, operando cuando la libertad económica altera las relaciones espaciales de los sujetos. La pregunta es qué sujetos buscó regular en el caso del Barrio Italia. Los antecedentes acusan una población residencial en retirada, lo que configuraría en actores sociales a los paseantes y locatarios, cuyos intereses no están sobre la calidad de vida, sino en la maximización de la renta devenida del ocio espacial y el deseo de una experiencia alternativa dentro de Santiago. Es una manifestación de producción alienada del espacio, donde las tramas recorridas por cada uno de estos actores se localizan en paralelo. Los murmullos y ruidos del barrio desnudan tal faceta, que resulta además en la construcción de otro indeseado.

2. Los ciclos del metaespacio no sólo pueden ser leídos desde la experiencia subjetiva del cotidiano, sino también desde la producción material del espacio como parte del paisaje urbano neoliberal. La cartografía del comportamiento para las patentes comerciales-Mapa 2- expone la condición líquida de estos ciclos, donde opera el interés sobre la renta comercial y, al mismo tiempo, el devenir político que ajusta las reglas del juego, cuando ellas dejan de operar. Los archipiélagos urbanos señalados buscan relevar la insularidad que los ciclos metaespaciales describen. En el entorno inmediato al barrio se generan murallas simbólicas que rechazan las prácticas masivas y retornan hacia lo exclusivo como un bien en sí mismo. Aquello acontece, empero, dentro de un espacio en el que lo residencial se ha limitado a unas cuantas familias, dejando lugar a una forma simbólica de traslape territorial: el barrio está en una zona central, pero podría estar en cualquier parte.

El barrio igual es bacán [estupendo] porque tiene mucho de diseño, arte, música, y eso se está expandiendo física y territorialmente. Te abre una tribuna, ya que si bien es un barrio que pudiese estar en Vitacura o La Dehesa, está acá [Providencia], está cerca, estamos en Santa Isabel, entonces es accesible, estamos cerca de un metro, hay micro, hay un millón de formas para llegar, estamos a 20 minutos caminando de Plaza Italia [...] Entonces eso llama a que se incorpore a este tipo de lugares, que la gente conozca de diseño y que pase un rato agradable [A. P4, 2017].

3. El metaespacio como trama es, también, una manifestación del activismo académico. Es imposible sostener categorías sin descripción e información crítica, suponiendo un reduccionismo científico a la forma inicial de todo aprendizaje: observar, reconocer, interpretar. Aquello que Lefebvre desarrolla desde el ritmanálisis, ilustra la validez de la empiria teóricamente 
situada que, si bien lo trabajado sobre Barrio Italia podría aplicarse a cualquier otra localidad, es pertinente cautelar dos ámbitos del espacio geográfico ineludibles: las condiciones de sitio y la excepcionalidad territorial.

El cosmopolitismo al que alude el título del trabajo es una de las producciones simbólicas del barrio. Una cáscara de área con alto impacto, como si fuera una proyección del Palermo Soho bonaerense, buscando construir una escena de consumo diferente y alternativa, a la vez que son oscurecidos los efectos de la esquilmación del suelo, sobre una trama urbana experimentada en distintas líneas que no se tocan en el mismo espacio. El metaespacio abre la oportunidad de quebrar aún más esta cáscara, develando el transitar de los escasos residentes, las clases trabajadoras de inmigrantes y los locatarios, quienes viven la idea de que se trata de otro lugar. El activismo académico propone ser la justificación para dicha ruptura.

\section{Bibliografía}

Arenas, Federico, Rodrigo Hidalgo y José Luis Coll (eds.) (2003), Los nuevos modos de gestión de la metropolización, Santiago de Chile, LOM.

Boyer, M. Christine (1992), "The imaginary real world of cibercities", Assemblage, núm. 18, pp. 114-127. Recuperado de https://www.jstor.org/stable/3171208? seq=1\#page_scan_tab_contents

Bridge, Gary (1995), "The space for class - on class analysis in the study of gentrification", Transactions of the Institute of British Geographers, vol. 20, núm. 2, pp. 236-247. Recuperado de http://www.jstor.org/stable/622434

Bunschoten, Raoul (2003), "Stirring still: The city soul and its metaspaces", Perspecta, núm. 34, pp. 56-65. Recuperado de https://www.jstor.org/stable/1567316? seq=1\#page_scan_tab_contents

Bunschoten, Raoul, Takuro Hoshino y Hélenè Binet (2001), Urban flotsam. Stirring the city, Rotterdam, 010 Publishers.

Castree, Noel (2013), Making sense of nature, Londres, Routledge.

Gárate, Manuel (2012), La revolución capitalista de Chile (1973-2003), Santiago de Chile, Universidad Alberto Hurtado.

Glass, Ruth (1989), Clichés of urban doom and other essays, Oxford, Blackwell Publishers.

Gravano, Ariel (2005), El barrio en la teoría social, Buenos Aires, Espacio.

Harvey, David (2006), Towards a theory of geographical uneven development, Londres, Verso.

Hernández, Roberto, Carlos Fernández y Pilar Baptista (2010), Metodología de la investigación, México, McGraw-Hill.

Hidalgo, Rodrigo, Daniel Santana y Voltaire Alvarado (2016), "Mitos, ideologías y utopías neoliberales de la producción del espacio: hacia una agenda de inves- 
tigación alternativa”, en Rodrigo Hidalgo, Daniel Santana, Voltaire Alvarado, Federico Arenas, Alejandro Salazar, Carlos Valdebenito y Luis Álvarez (orgs.), En las costas del neoliberalismo. Naturaleza, urbanización y producción inmobiliaria: experiencias en Chile y Argentina, Santiago de Chile, Geolibros, pp. 24-66.

Hojman, David (1974), Desarrollo regional y planificación regional: efectos del modelo económico de la Unidad Popular sobre el desarrollo espacial geográfico. El caso chileno, Caracas, Universidad Central de Venezuela.

INE (Instituto Nacional de Estadísticas) (2016a), Datos precenso de vivienda y población de 2016, Santiago, Chile, INE. Recuperado de http://www.censo2017. cl/resultados-precenso-2016/ (21 de agosto de 2017).

INE (Instituto Nacional de Estadísticas (2016b), Estadísticas demográficas y vitales. Proyecciones 2002-2020, Santiago, Chile, INE. Recuperado de http://www.ine. cl/estadisticas/demograficas-y-vitales (21 de agosto de 2017).

Lees, Loretta, Hyun Bang Shin y Ernesto López-Morales (2016), Planetary gentrification, Oxford, Polity Press.

Lefebvre, Henri (1970), Lógica dialéctica, lógica formal, Madrid, Siglo XXI.

Lefebvre, Henri (2007), Rhythmanalysis. Space, time and every day life, Norfolk, Continuum.

Lévy, Bertrand (2006), “Geografía y literatura”, en Daniel Hiernaux y Alicia Lindón (eds.), Tratado de geografía humana, México, Anthropos, pp. 460-480.

Lindón, Alicia (2011), "Revisitar la concepción de lo social para una geografía constructivista", en Perla Zusman, Rogerio Haesbaert, Hortensia Castro y Susana Adamo (eds.), Geografias culturales. Aproximaciones, intersecciones y desafios. Buenos Aires, Filo, UBA, pp. 177-212.

Lussault, Michel (2015), El hombre espacial. La construcción social del espacio humano, Buenos Aires, Amorrortu.

Massey, Doreen (2012), "La filosofía y la política de la espacialidad: algunas consideraciones", en Abel Albet y Nuria Benach (eds.), Un sentido global del lugar, Barcelona, Icaria, pp. 156-181.

Municipalidad de Providencia (2016), Portal de transparencia al otorgamiento de patentes comerciales, Municipalidad de Providencia, Chile. Recuperado de http:// transparencia.providencia.cl/tact/Carpeta/Listado/102 (21 de agosto de 2017).

Peet, Richard, Paul Robbins y Michael Watts (2011), Global political ecology, Nueva York, Routledge.

Pereira, Paulo Cesar Xavier (2016a), "Processos e problemas na urbanização da América Latina: teoria e história”, Territorios, núm. 34, pp. 35-58. Recuperado de http://www.redalyc.org/html/357/35744556002/

Pereira, Paulo Cesar Xavier (2016b), "El vaciamiento de la noción de gentrificación y sus consecuencias para la lucha urbana y el derecho a la ciudad", ponencia presentada en el Congreso Internacional Constested Cities 2016, Madrid, Universidad Autónoma de Madrid, 4 a 7 de julio. Recuperado de http://contestedcities.net/working-papers/2016/el-vaciamiento-de-la-nocion-de-gentrificacion- 
y-sus-consecuencias-para-la-lucha-urbana-y-el-derecho-de-la-ciudad/

Robinson, Jennifer (2006), Ordinary cities: Between modernity and development, Londres, Routledge.

Sabatini, Francisco e Isabel Brain (2008), “La segregación, los guetos y la integración social urbana: mitos y claves", Eure, vol. 34, núm. 103, pp. 5-26. Recuperado de http://dx.doi.org/10.4067/S0250-71612008000300001

Santos, Milton (2004), Por otra globalización: del pensamiento único a la conciencia universal, Bogotá, Convenio Andrés Bello.

Schlack, Elke y Neil Turnbull (2009), "La colonización de barrios céntricos por artistas", Revista 180, núm. 24, pp. 2-5. Recuperado de http://www.revista180.cl/ index.php/revista180/article/view/262

Smith, Neil (2012), La nueva frontera urbana. Ciudad revanchista y gentrificación, Madrid, Traficantes de Sueños.

Soja, Edward (1996), Thirdespace. Journeys to Los Angeles and other real-andimagined places, Cambridge, Blackwell Publishing.

Solimano, Andrés (2013), Capitalismo a la chilena y la prosperidad de las élites, Santiago de Chile, Catalonia.

Valdivia, Verónica, Rolando Álvarez y Julio Pinto (2006), Su revolución contra nuestra revolución. vol. 1, Izquierdas y derechas en el Chile de Pinochet (19731981), Santiago de Chile, LOM.

Vásquez, Ana María (2016), “Feminismo y 'extractivismo urbano’: notas exploratorias”, Nueva Sociedad, núm. 256, pp. 153-163. Recuperado de http://nuso.org/ media/articles/downloads/10. TC_Vazquez_265.pdf

Wacquant, Loïc (2008), "Relocating gentrification: The working class, science and the state in recent urban research", International Journal of Urban and Regional Research, vol. 32, núm. 1, pp. 198-205. doi:10.1111/j.1468-2427.2008.00774.x

White, Hayden (1992), Metahistoria. La imaginación histórica en la Europa del siglo XIX, México, Fondo de Cultura Económica.

Wyly, Elvin (2015), "Gentrification on the planetary urban frontier: The evolution of Turner's noösphere”, Urban Studies, vol. 52, núm. 14, pp. 2515-2550. doi:10. $1177 / 0042098015601362$

\section{Acerca de los autores}

Rodrigo Hidalgo Dattwyler es doctor en Geografía. Actualmente es profesor titular y jefe del Programa de Doctorado en Geografía del Instituto de Geografía, de la Pontificia Universidad Católica de Chile (UC), e investigador responsable de distintos proyectos patrocinados por el Fondo Nacional de Desarrollo Científico y Tecnológico (Fondecyt, Chile). Es autor del libro La vivienda social en Chile y la producción del espacio urbano en Santiago, UC / Centro de Investigaciones Diego Barrios Arana, 2005; coordinador 
(junto con Michael Janoschka) del libro La ciudad neoliberal, Santiago, UC, 2014; y coordinador (junto con Daniel Santana, Voltaire Alvarado, Federico Arenas, Alejandro Salazar, Carlos Valdevenito y Luis Álvarez) del libro En las costas del neoliberalismo, Santiago, UC / UCV, 2016. Dichos trabajos expresan la intensa cooperación establecida entre estudiosos de diversos campos del saber geográfico. Actualmente dirige, como investigador principal, el proyecto Fondecyt 1150360, "La política de vivienda social en las áreas metropolitanas de Santiago y Valparaíso: entre la desigualdad y sostenibilidad del desarrollo urbano (1992-2014)".

Voltaire Alvarado Peterson es maestro en Geografía y Geomática. Es profesor del Instituto de Geografía de la Pontificia Universidad Católica de Chile (UC). Ha publicado artículos en revistas científicas internacionales y ha participado en capítulos de libros, entre los que destacan los que aparecen en Las costas del neoliberalismo, donde también funge como coordinador, junto con Rodrigo Hidalgo Dattwyler et al., Santiago, UC / UCV, 2016. Es candidato a doctor en Geografía por la UC.

Daniel Santana Rivas es maestro en Geografía por la Universidad Nacional de Colombia. Es investigador junior de Colciencias y candidato a doctor en Geografía por la Pontificia Universidad Católica de Chile (UC). Ha publicado artículos en revistas científicas internacionales; además participó en la coordinación (junto a Rodrigo Hidalgo Dattwyler et al.) del libro En las costas del neoliberalismo, Santiago, UC / UCV, 2016.

Alex Paulsen Espinoza es maestro en Geografía y Geomática y estudiante del Programa de Doctorado en Geografía de la Pontificia Universidad Católica de Chile (UC). Ha publicado artículos en revistas nacionales e internacionales, así como capítulos de libros, destacando el que aparece en $L a$ ciudad neoliberal (coordinado por Rodrigo Hidalgo y Michael Janoschka), Santiago, UC, 2014; y en la obra en homenaje al profesor Axel Borsdorf, Die Welt Verstehen, editado por la Universidad de Innsbruck, Austria, 2016.

Fecha de recepción: 30 de enero de 2017. Fecha de aceptación: 9 de junio de 2017. 